\title{
HOXB4 Increases Runx1 Expression to Promote the de novo Formation of Multipotent Hematopoietic Cells
}

\author{
Nadine Teichweyde Peter A. Horn Hannes Klump \\ Institute for Transfusion Medicine, University Hospital Essen, Essen, Germany
}

\section{Keywords}

HOXB4 - Runx1 - Hematopoietic stem cells .

Pluripotent stem cells $\cdot$ Hemogenic endothelium

\section{Summary}

Background: The de novo generation of patient-specific hematopoietic stem and progenitor cells from induced pluripotent stem cells (iPSCs) has become a promising approach for cell replacement therapies in the future. However, efficient differentiation protocols for producing fully functional human hematopoietic stem cells are still missing. In the mouse model, ectopic expression of the human homeotic selector protein HOXB4 has been shown to enforce the development of hematopoietic stem cells (HSCs) in differentiating pluripotent stem cell cultures. However, the mechanism how HOXB4 mediates the formation of HSCs capable of long-term, multilineage repopulation after transplantation is not well understood yet. Methods: Using a mouse embryonic stem (ES) cell-based differentiation model, we asked whether retrovirally expressed HOXB4 induces the expression of Runx1/AML1, a gene whose expression is absolutely necessary for the formation of definitive, adult HSCs during embryonic development. Results: During ES cell differentiation, basal expression of Runx 1 was observed in all cultures, irrespective of ectopic HOXB4 expression. However, only in those cultures ectopically expressing HOXB4, substantial amounts of hematopoietic progenitors were generated which exclusively displayed increased Runx1 expression. Conclusions: Our results strongly suggest that HOXB4 does not induce basal Runx 1 expression but, instead, mediates an increase of Runx 1 expression which appears to be a prerequisite for the formation of hematopoietic stem and progenitor cells.

(c) 2017 S. Karger GmbH, Freiburg

\section{Introduction}

Ex vivo generation of hematopoietic stem, progenitor and mature effector cells from pluripotent stem cells, such as induced pluripotent stem cells (iPSCs), are particularly interesting for medical use because such a technology would allow for the generation of either patient-specific autologous or 'off-the-shelf allogeneic blood products for a wide range of transplantation and transfusion settings. Therefore, major efforts have been made over the past years to reliably and stably generate and expand sufficient numbers of hematopoietic stem cells (HSCs) from PSCs in vitro. Despite the significant progress made, HSCs capable of long-term, multilineage repopulation after transplantation have only been generated with mouse cells and only when the transcription factor HOXB4 was ectopically expressed [1-3]. HOXB4 belongs to the family of homeotic selector proteins encoded by homeobox (HOX) genes which are well known for their importance to confer positional information to cells and tissues during embryonic development and to control stem cell self-renewal and differentiation in the adult organism [4]. Human HOXB4, in particular, has repeatedly been demonstrated to enhance the hematopoietic potential of differentiating embryonic stem cells (ESCs) in vitro $[1,3,5-9]$ and to mediate an expansion of adult HSCs of mice and humans [10-12]. However, the underlying mechanisms how HOXB4 mediates these valuable effects are still not understood very well, thus making it a challenging process to decipher the best conditions for translating the results from the mouse to the human system. Therefore, we focused on major cellular stages known to be important for hematopoietic development in vivo and evaluated whether HOXB4 interferes at those decision points during mouse ESC differentiation in vitro. During ontogeny, the first HSCs with multilineage reconstitution and long-term repopulation potential arise from major arteries [13, 14]. Adult-type, 'definitive' HSCs can first be detected on the ventral floor of the dorsal aorta in mice around embryonic day 10 (E10), in humans around E30 [15-20]. Within the ventral endothelial lining of the

\section{KARGER}

() 2017 S. Karger GmbH, Freiburg

Fax +497614520714 
Fig. 1. Experimental procedure for determining the influence of HOXB4 on Runx1 expression. A Design of the employed $\gamma$-retroviral HOXB4 co-expression vector. The vector co-expresses a fluorescent protein (mPlum) together with HOXB4 or a 4Tam-inducible fusion protein, HOXB4 ${ }^{\mathrm{ERT}}$. Separation of the co-expressed fluorescent protein is mediated by foot-and-mouth disease virus (FMDV) $2 \mathrm{~A}^{\text {esterase }}$. B An outline of the experimental procedure is depicted. ES cells were differentiated in suspension as EBs for 6 days, dissociated and subsequently co-cultured on OP9 stromal cells for further 5 days.
A

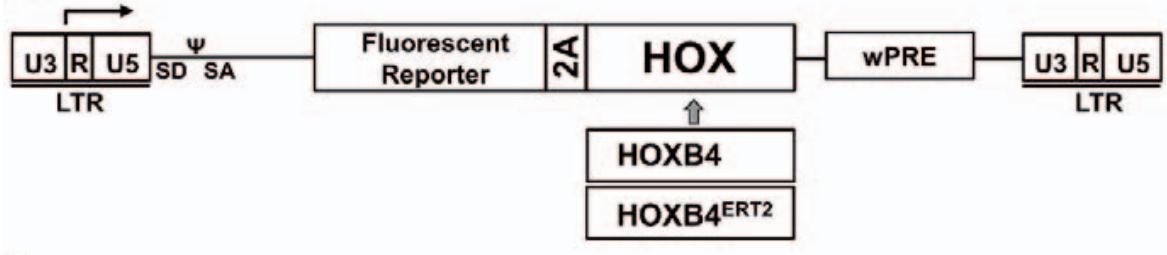

B

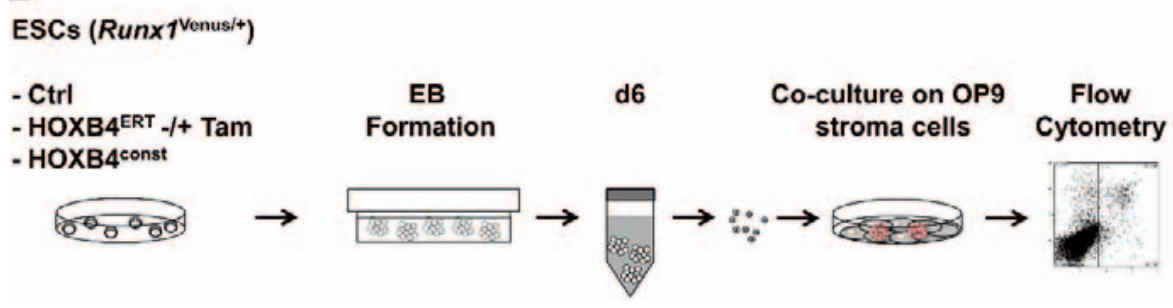

aorta, hematopoietic stem and progenitor cells (HSPCs) are generated by so-called hemogenic endothelium (HE) cells. These specialized, hematopoiesis-primed endothelial cells undergo a process termed endothelial-to-hematopoietic transition (EHT) to become non-adherent, migratory hematopoietic cells [14, 21, 22]. The runt-related transcription factor 1 (RUNX1/AML1) is absolutely required for this process [23] as a homozygous deletion of the Runx 1 gene is embryonically lethal at E12.5 due to the lack of HSC formation [24].

In this work, we addressed the question whether ectopically expressed HOXB4 promotes Runx1 expression and, thereby the development of definitive HSCs. Employing cells of a Runx1-reporter ESC line [25], we here demonstrate that HOXB4 mediated an increase of Runx1 expression in cells already expressing basal levels of this gene. This 'pulse' of Runxl expression correlated with the formation of developmentally early CD41+ CD45+ hematopoietic cells.

\section{Material and Methods}

\section{ES-Cell Culture, Embryoid Body Formation and Hematopoietic} Differentiation

Run $x 1^{\text {Venus/+ }}$ mouse ESCs were transduced with retroviral vectors expressing a fluorescence protein (mPlum or tdTomato) alone or together with HOXB4 variants co-translationally separated from each other by a picornaviral $2 \mathrm{~A}^{\text {esterase }}[12]$. Transduced cells were purified by flow cytometry-based cell sorting and grown on growth-arrested murine CF1-embryonic fibroblasts (MEFs) in knockout DMEM (Gibco, ThermoFisher Scientific, Grand Island, NY, USA) medium containing $15 \%(\mathrm{~V} / \mathrm{v})$ fetal calf serum, $2 \mathrm{mmol} / \mathrm{l} \mathrm{L}$-glutamine, $1.5 \times 10^{-4}$ $\mathrm{mol} / \mathrm{l}$ monothioglycerol (MTG) (Sigma-Aldrich, Taufkirchen, Germany), pretested leukemia inhibitory factor, and $1 \%(\mathrm{v} / \mathrm{v})$ penicillin/streptomycin. Embryoid body (EB) formation was performed in suspension after removal of MEFs by magnetic activated cell sorting (MACS; Feeder Removal MicroBeads mouse; Miltenyi Biotec, Bergisch-Gladbach, Germany). 5,000 ES cells/ml were plated in IMDM medium (Lonza, Switzerland), 15\% ( $/ \mathrm{v}$ ) fetal calf serum, $5 \%(\mathrm{v} / \mathrm{v})$ protein-free hybridoma medium II (Gibco), 2 mmol/l L-glutamine, $0.5 \%(\mathrm{v} / \mathrm{v})$ penicillin/streptomycin (Sigma-Aldrich), $50 \mu \mathrm{g} / \mathrm{ml}$ ascorbic acid (Sigma Aldrich), $300 \mu \mathrm{g} / \mathrm{ml}$ iron-saturated transferrin (Sigma-Aldrich), and $4 \times 10^{-4} \mathrm{MTG}$. EBs were dissociated by $0.05 \%$ trypsin-EDTA treatment at $37^{\circ} \mathrm{C}$ for $2-5 \mathrm{~min}$. Dissociated day 6 EBs were co-cultured on OP9 stroma cells in $10 \%$ fetal calf serum supplemented with mSCF, mTPO, hFlt-3L, and hVEGF (STFV [48]) (PeproTech, Hamburg, Germany). Cells were grown at $37^{\circ} \mathrm{C}$ in $5 \% \mathrm{CO}_{2}$ in a humidified chamber.

\section{Flow Cytometry and Microscopy}

ESC-derived hematopoietic cells were analyzed by flow cytometry (FACS Aria III, BD Biosciences, Franklin Lakes, NJ, USA) using monoclonal, fluorochrome-conjugated antibodies directed against the surface markers CD41 and CD45 (CD41 (clone eBioMWReg30), CD45 (clone 30-F11); eBioscience, San Diego, CA, USA). Photos were taken using an Observer D1 microscope (Zeiss, Jena, Germany, filter: 46 HE YFP (BP 500/25, FT 515, BP 535/30). Axio Vision Software 4.8 was used for image processing (Zeiss).

Colony Assays

For colony formation assays, 500 ESC-derived hematopoietic cells each were placed in semisolid methylcellulose supplemented with rmSCF, rmIL-3, rhIL-6, and rhEpo (M3434 MethoCult; Stem Cell Technologies, Vancouver, BC, Canada) after purification by flow cytometry-based cell sorting and grown in 24 wells for 12 days at $37^{\circ} \mathrm{C}, 5 \% \mathrm{CO}_{2}$ atmosphere in a humidified chamber.

\section{Results}

To test whether HOXB4 influences Runx1 transcription, we utilized mouse ESCs carrying the coding sequence of the 'Venus' fluorescence protein under the control of the proximal P2 promoter of the Runx1 gene (Runx $\left.1^{\text {Venus/+ }}\right)$ [25]. In these cells, we retrovirally expressed HOXB4 either in a constitutively active form $\left(\mathrm{HOXB} 4^{\text {const }}\right.$ ) or as a 4-hydroxytamoxifen(Tam)-inducible fusion protein consisting of HOXB4 and the hormone-binding domain of the estrogen receptor $\left(\mathrm{HOXB} 4^{\mathrm{ERT}}\right)$ [5], together with a fluorescent protein (mPlum or tdTomato) (fig. 1A). During differentiation as EBs for 6 days and subsequent co-culture on OP9 stromal cells, we periodically monitored Venus(Runx1) expression (fig. 2) and the appearance of CD41+ and CD45+ hematopoietic progenitors (fig. 3). Within the first 6 days, a slightly lower proportion of Runx1+ or Flk1+ cells was observed in day 4-6 EBs ectopically expressing HOXB4 (fig. 2, bottom row). However, this was a variable effect most likely attributable to the known mutual interdependence of fibroblast growth factor (FGF) 
Fig. 2. Initiation of Flk1 und Runx1 expression during EB differentiation. Run $x 1^{\text {Venus/+ }}$ ES cells were used to monitor Runx1 expression daily from day 2 to day 6 of EB development. Venus(Runxl) and Flk1 expression is shown for mPlum transduced control cells and cells retrovirally expressing mPlum-2A-HOXB4 (HOXB4 ${ }^{\text {const }}$ ) or the noninduced HOXB4-ERT fusion-protein (mPlum-2A$\mathrm{HOXB}_{4}{ }^{\mathrm{ERT}}$; HOXB4 ${ }^{\mathrm{ERT}}$-Tam). A typical result of five independent experiments is shown.

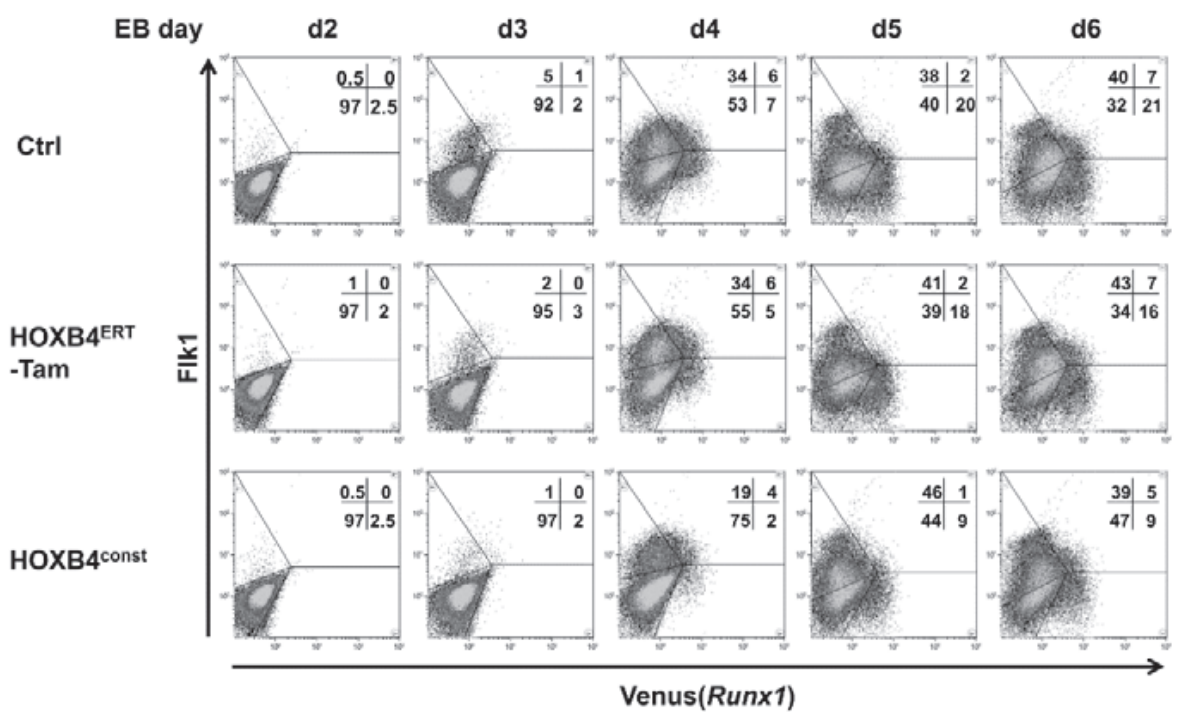

A

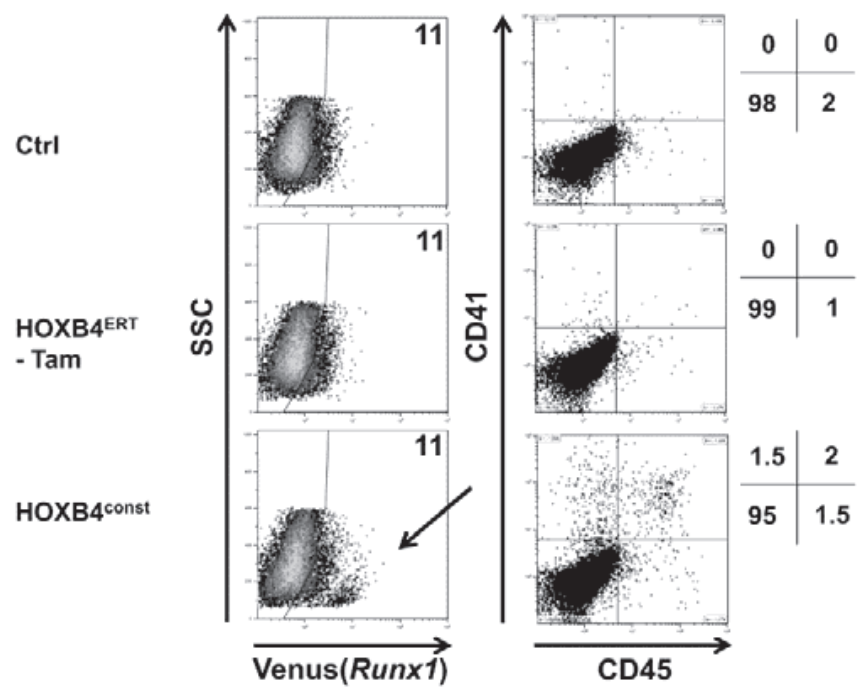

B

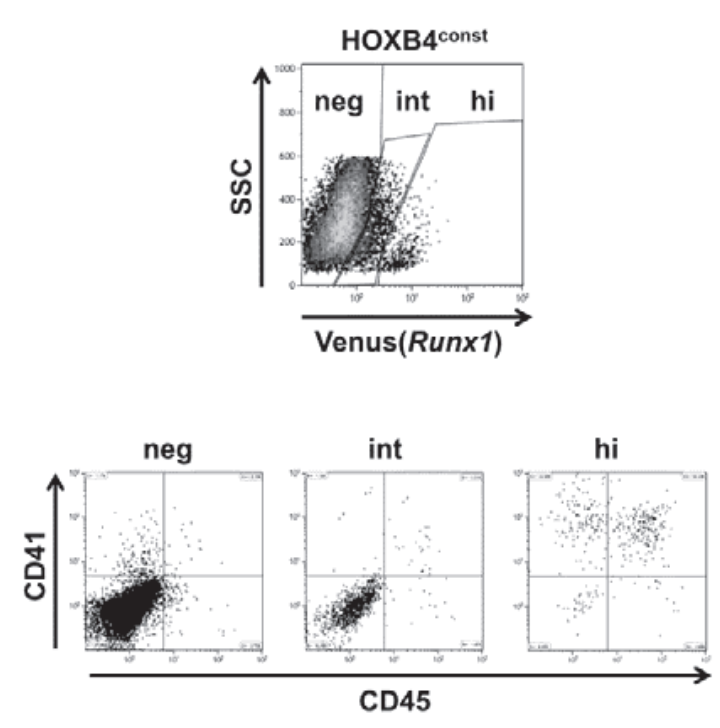

C

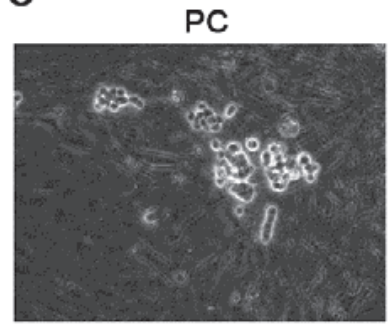

Venus(Runx1)
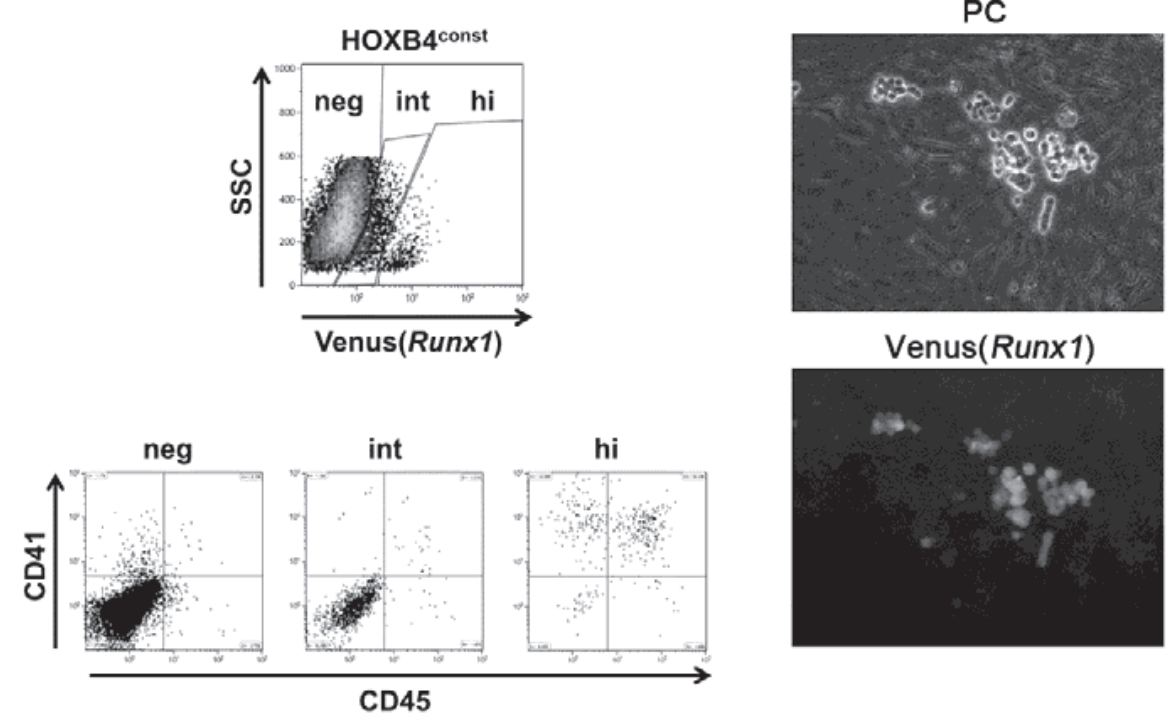
co-culture. Phase contrast (PC, upper panel) and fluorescence (lower panel) images are shown. 


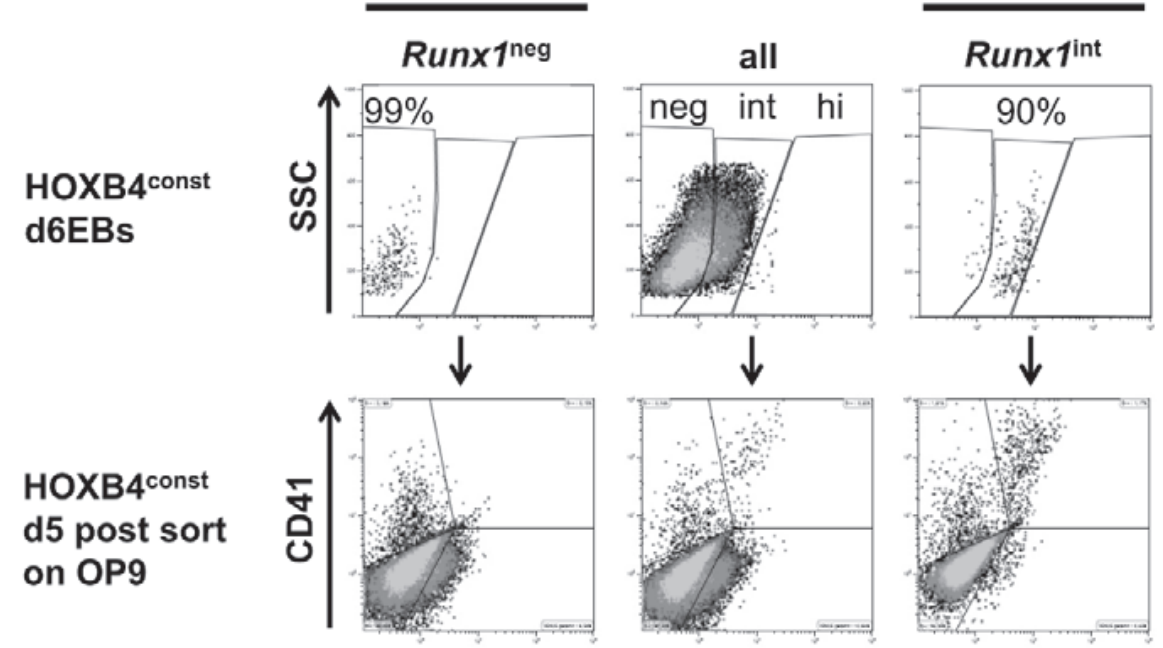

B

Fig. 4. Basal Runx 1 expression is a prerequisite for HOXB4 mediated development of Run $x 1^{\mathrm{hi}} / \mathrm{CD} 41^{\mathrm{hi}}$ hematopoietic suspension cells. A Venus(Runx $I^{\text {neg }}$ ) and Venus $\left(R u n x I^{\text {int }}\right)$ cells were purified from dissociated day 6 EBs derived from HOXB4 $4^{\text {const }}$ and HOXB4 ${ }^{\mathrm{ERT}}$ transduced Venus(Runx1) ESCs (upper row, mid-panel, 'all') by flow cytometry-based cell sorting (a representative post-sort re-analysis is shown: upper row, left panel, 'Runx $1^{\text {neg' }}$ and right

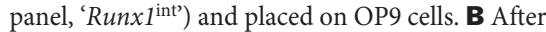
sorting, $100 \mathrm{nmol} / \mathrm{l}$ (Tam were added to the cells expressing inducible $\mathrm{HOXB} 4{ }^{\mathrm{ERT}}$. After 5 days of co-culture on OP9 cells, CD41 and Venus(Runx1) expression were analyzed again. $\mathrm{CD} 4 \mathrm{l}^{\mathrm{hi}}$ cells were only obtained when HOXB4 was expressed or induced in the Runx $I^{\text {int }}$ cells. Non-sorted masscultures (mid-panels), sorted populations (left and right panels). C Correlation of HOXB4 expression levels with Runxl expression.

\section{HOXB4ERT d5 post sort on OP9 +100 nM Tam}

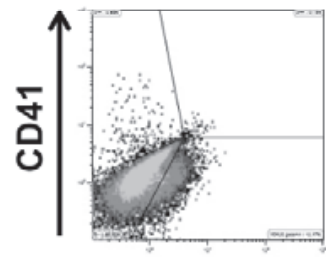

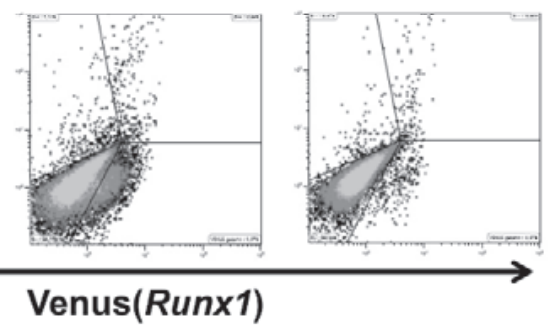

C
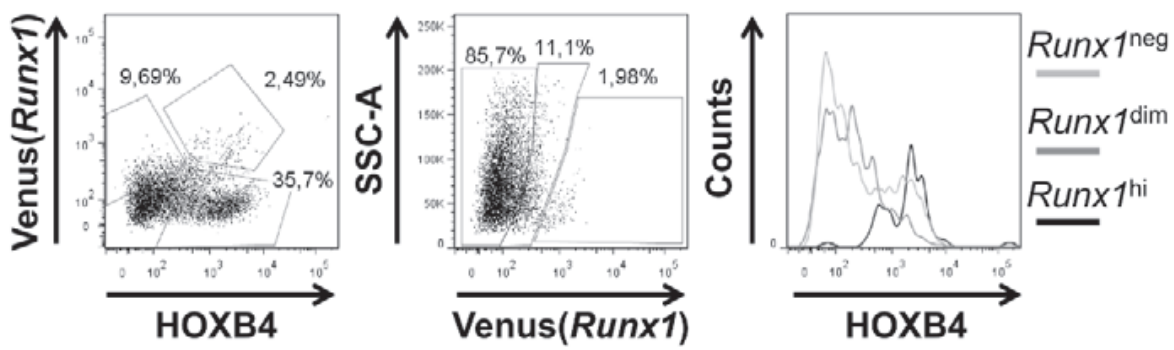

signaling and HOXB4 activity occasionally resulting in a slight delay of mesoderm specification [5]. During subsequent co-cultivation of dissociated day 6 EBs on OP9 cells, a small subpopulation displaying increased Runx1 expression levels was detected. This population was only present when HOXB4 was expressed (in average accounting for $14.8 \%$ of all Runx $1+$ cells) (fig. 3B) and contained almost all of the CD41+ and CD45+ hematopoietic progenitors (fig. 3A, B). In well accordance, Venus+ suspension clusters almost exclusively appeared in this group (fig. 3C) and were sparsely observed in the non-induced HOXB4 $4^{\mathrm{ERT}}$ controls (HOXB4 ${ }^{\text {ERT }}$ without Tam) or in the Plum-transduced control population. To test if HOXB4 induces Runx1 expression in Runx $1^{\text {neg }}$ cells or if a basal Runx 1 expression is necessary for the observed increase, we purified both subpopulations from dissociated day $6 \mathrm{EBs}\left(\right.$ Run $x 1^{\text {neg }}$, Run $x 1^{\text {int }}$ ) (fig. 3, 4). Noteworthy, we never detected a Runx ${ }^{\text {hi }}$ subpopulation within EBs at this time point. After further 5 days of co-cultivation on OP9 cells, we again determined the presence of CD41+ and/or CD45+ hema-

topoietic progenitors. Only those cells expressing basal levels of Runx1 developed into hematopoietic cells which expressed increased levels of Runx1 and CD41 when HOXB4 was overexpressed, either constitutively (fig. $4 \mathrm{~A}$, right panels, $\mathrm{HOX}^{\text {const }}$ ) or after induction with $100 \mathrm{nmol} / \mathrm{l}$ tamoxifen post sorting (fig. 4B, HOXB4 ${ }^{\mathrm{ERT}}$ ). Noteworthy, increased HOXB4 expression tightly correlated with increased Runx1 expression (fig. 4C). To also functionally test which of these populations contained hematopoietic progenitor activities, we performed colony forming cell assays with the purified Runx $1^{\text {int/neg }}$ and Runx $1^{\text {hi }}$ cell populations. Only the Runx $1^{\text {hi }} / \mathrm{CD} 41+$ fraction contained substantial colony forming activities, including multipotent colony-forming units granulocyte, erythrocyte, monocyte/macrophage, megakaryocyte (CFU-GEMMs) (fig. 5). Thus, using the mouse ES/EB differentiation model our results strongly suggest that ectopic HOXB4 expression promotes hematopoietic development at least by mediating an increase of Runx1 expression in those cells which had previously initiated its expression at basal levels. The results also in- 
Fig. 5. Runx $1^{\text {hi }}$ population contains the main hematopoietic colony-forming activity. A After exclusion of CD140b+ OP9 cells, CD41 ${ }^{\text {low }} R u n x 1^{\text {neg }}$ or CD $41^{\text {hi }}$ Run $x 1^{\text {hi }}$ were purified by flow cytometry. The percentages of CD41+ and CD45+ cells presort are indicated. B 500 cells of each purified population were tested for the presence of hematopoietic colony forming cells in triplicate. Columns represent the total number colonies formed after 12 days per 500 cells seeded. The mean proportions of different colony types are depicted $\pm \mathrm{SD}$. $\mathrm{M}=$ CFU-monocyte/macrophage; $\mathrm{G}=\mathrm{CFU}$-granulocyte; CFU-E = erythroid colony forming units; $\mathrm{GM}=\mathrm{CFU}$-granulocyte-monocyte/macrophage; GEMM = CFU-granulocyte/erythroid/monocytemacrophage/megakaryocyte.
A

B

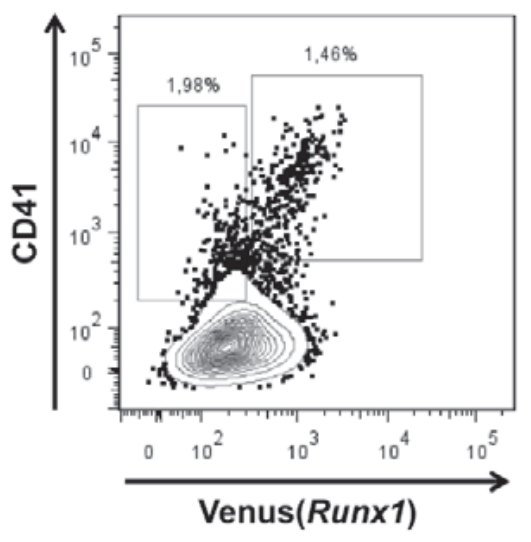

dicate that the process of endothelial-to-hematopoietic transition, which is a key maturation step during HSC development, is only triggered above a certain threshold of Runx1 expression.

\section{Discussion}

To date, the main developmental stage at which ectopically expressed HOXB4 promotes the development of definitive HSPCs from differentiating mouse pluripotent stem cells in vitro is not known. Because the transcription factor RUNX1 is absolutely essential for their development [26], we here investigated whether HOXB4 regulates its expression, using cells of a Runx1 reporter ES cell line [25]. We demonstrated that ectopic HOXB4 expression mediated an increase in Runx1 expression in cells already expressing basal levels of Runx1. This was accompanied by the formation of suspension cells which displayed many hallmarks of hematopoietic cells, including the expression of the cell surface marker CD41 (integrin aIIb), the developmental earliest known marker of hematopoietic progenitors $[27,28]$. These cells further matured towards CD41- CD45+ cells, an important criterion for definitive, adult HSCs. In previous work, we and others have repeatedly shown that such ES cell-derived hematopoietic cells mediate multilineage, longterm repopulation after in vivo transplantation in mice [2, 3, 5-7].

Basal expression of Runx1 was a prerequisite for the observed increase mediated by HOXB4 in a subpopulation of those cells. Interestingly, increased Runx1 expression correlated well with higher expression levels of HOXB4, supporting the concept of dosage-dependent effects of this homeotic selector protein, as previously described $[3,11,29]$. In vivo, basal Runx1 expression has been shown to be a mandatory priming event for endothelial cells to become definitive HSCs, prior to their transition to suspension cells [30]. Our in vitro results indicate that only increased Runxl expression triggers the process of EHT which represents a key and rate-limiting step in the formation of HSPCs. A tempting interpretation is that RUNX1 protein needs to exceed a certain threshold concentration to initiate EHT. Whether or not this also holds true for the formation of HSPCs from HE cells in the dorsal aorta in vivo is still unclear. There is some evidence that this may be the case, though [31, 32].

Transcription of the Runx1 locus is controlled by two promoters: the proximal P2 promoter which controls basal, broad expression and a distal P1 promoter which is activated during hematopoietic specification in the embryo and later on in definitive HSCs $[33,34]$. Initiation of P1 activity appears to be controlled by the loss of promoter methylation and by enhancer regions located in the first intron between P1 and P2. Interestingly, HOXB4 was shown to physically bind to the $\mathrm{P} 1$ promoter in mouse ESC-derived CD41+ cells, in vitro (EBd6/OP9d6 and EBd6/OP9d11). Its presence was accompanied by a decreased binding by the maintenance DNA methyltransferase DNMT1 and an increased occupancy by acetylated histone $\mathrm{H} 3 \mathrm{~K} 9 \mathrm{Ac}$ which marks transcriptionally active chromatin, as shown by chromatin immunoprecipitation experiments [35]. However, whether selective demethylation of the P1 promoter is a cause or consequence of HOXB4 binding has not been clarified yet. Within the dorsal aorta Runx1 expression in vivo is tightly controlled by the local environment with subaortic mesenchymal cells being crucial for inducing its basal expression [36]. This interaction obviously confers hematopoietic competence to a subset of endothelial cells, which become the HE. Activation of a somitic Wnt-FGF-NOTCH signaling axis plays an essential role in mediating induction of Runx1 expression, as has been mainly shown in the zebrafish model [37-40]. During early, non-cell-autonomous hematopoietic specification, Wnt16 is required for inducing somitic expression of the Notch-ligand dlc (the DLL3 orthologue of mammals), with FGF acting as a critical relay within the somites. Without $d l c$ induction mediated by FGF signaling in combination with upregulation of dld (the orthologue of mammalian DLL1) by a hitherto unknown pathway, Runx1 induction is abrogated [39]. HOXB4 appears to, at least in part, promote hematopoietic specification during this non-cell-autonomous stage by upregulation of a secreted modulator of Wnt signaling, FRZB [41]. How signals from the somites are then relayed to the endothelial precursors of hematopoietic cells is not clear yet, but activation of bone morphogenetic protein (BMP) signaling as a consequence of local 
FGF signaling inhibition appears to be essential [38]. During ESC differentiation in vitro, suppression of FGF signaling mediated by HOXB4 also appears to promote hematopoietic progenitor formation, as we have previously shown [5]. During the final, cell-autonomous phase in HE cells, activation of NOTCH1 is essential, where it induces the expression of Gata2, together with the transcription factor RBPjk/CSL [42]. GATA2, in turn, binds to the HE-specific +23 intronic enhancer element of Runx1 in a complex containing SCL1, LMO2, and LDB1 to induce its expression [43, 44]. Moreover, GATA2 and RUNX1 directly interact in a higher order transcription factor complex resulting in a further increase of Runxl transcription in an autoregulatory feed-forward loop [45]. Ultimately, the concurrent presence of both GATA2 and RUNX1 is necessary to induce EHT and early HSPC formation [46]. Based on our results, one can envision that HOXB4 physically participates in this complex and, by this, promote increased expression of Runx1. However, if this is the case and how the binding of HOXB4 leads to further upregulation of Runx1, remains to be answered.

In summary, we have demonstrated that ectopic HOXB4 expression promoted the upregulation of Runxl expression which, in turn, is tightly correlated with the generation of multipotent he- matopoietic progenitors. Elucidation of the underlying molecular mechanism(s) how HOXB4 controls Runx1 transcription at the endothelial-to-hematopoietic transition stage may allow the development of an alternative, drug-based strategy which mimics HOXB4 activity at this critical and rate-limiting developmental step [47]. Provided that our findings can be translated to the human system, these results will be of particular relevance for the development of improved protocols for directed hematopoietic differentiation of human iPSCs.

\section{Acknowledgments}

We wish to thank Shin-Ichi Nishikawa (RIKEN Center for Developmental Biology, Minatojima-Minamimachi, Chuou-Ku, Kobe, Japan) for providing the Venus-Runx1 mouse reporter ESCs. This work was supported by the Deutsche Forschungsgemeinschaft (DFG grants KL1311/5-1 and KL1311/8-1).

\section{Disclosure Statement}

None of the authors has any potential conflict of interest related to this manuscript.

\section{References}

1 Helgason CD, Sauvageau G, Lawrence HJ, Largman C, Humphries RK: Overexpression of HOXB4 enhances the hematopoietic potential of embryonic stem cells differentiated in vitro. Blood 1996;87:2740-2749.

2 Kyba M, Perlingeiro RC, Daley GQ: HoxB4 confers definitive lymphoid-myeloid engraftment potential on embryonic stem cell and yolk sac hematopoietic progenitors. Cell 2002;109:29-37.

3 Pilat S, Carotta S, Schiedlmeier B, Kamino K, Mairhofer A, Will E, Modlich U, Steinlein P, Ostertag W, Baum C, Beug H, Klump H: HOXB4 enforces equivalent fates of ES-cell-derived and adult hematopoietic cells. Proc Natl Acad Sci U S A 2005; 102: 12101-12106.

4 Gehring WJ: Homeo boxes in the study of development. Science 1987;236:1245-1252.

5 Schiedlmeier B, Santos AC, Ribeiro A, Moncaut N, Lesinski D, Auer H, Kornacker K, Ostertag W, Baum C, Mallo M, Klump H: HOXB4's road map to stem cell expansion. Proc Natl Acad Sci U S A 2007; 104:1695216957.

6 Lesinski DA, Heinz N, Pilat-Carotta S, Rudolph C, Jacobs R, Schlegelberger B, Klump H, Schiedlmeier B: Serum- and stromal cell-free hypoxic generation of embryonic stem cell-derived hematopoietic cells in vitro, capable of multilineage repopulation of immunocompetent mice. Stem Cells Transl Med 2012;1: 581-591.

7 Chan KM, Bonde S, Klump H, Zavazava N: Hematopoiesis and immunity of HOXB4-transduced embryonic stem cell-derived hematopoietic progenitor cells. Blood 2008;111:2953-2961.

8 Klump H, Teichweyde N, Meyer C, Horn PA: Development of patient-specific hematopoietic stem and progenitor cell grafts from pluripotent stem cells, in vitro. Curr Mol Med 2013;13:815-820.

9 Pilat S, Carotta S, Klump H: Development of hematopoietic stem and progenitor cells from mouse embryonic stem cells, in vitro, supported by ectopic human HOXB4 expression. Methods Mol Biol 2013;1029:129-147.
10 Sauvageau G, Thorsteinsdottir U, Eaves CJ, Lawrence HJ, Largman C, Lansdorp PM, Humphries RK: Overexpression of HOXB4 in hematopoietic cells causes the selective expansion of more primitive populations in vitro and in vivo. Genes Dev 1995;9:1753-1765.

11 Schiedlmeier B, Klump H, Will E, Arman-Kalcek G, Li Z, Wang Z, Rimek A, Friel J, Baum C, Ostertag W: High-level ectopic HOXB4 expression confers a profound in vivo competitive growth advantage on human cord blood CD34+ cells, but impairs lymphomyeloid differentiation. Blood 2003;101:1759-1768.

12 Klump H, Schiedlmeier B, Vogt B, Ryan M, Ostertag W, Baum C: Retroviral vector-mediated expression of HoxB4 in hematopoietic cells using a novel coexpression strategy. Gene Ther 2001;8:811-817.

13 de Bruijn MFTR, Speck NA, Peeters MCE, Dzierzak E: Definitive hematopoietic stem cells first develop within the major arterial regions of the mouse embryo. EMBO J 2000;19:2465-2474.

14 Jaffredo T, Gautier R, Eichmann A, Dieterlen-Lievre F: Intraaortic hemopoietic cells are derived from endothelial cells during ontogeny. Development 1998; 125:4575-4583.

15 Muller AM, Medvinsky A, Strouboulis J, Grosveld F, Dzierzak E: Development of hematopoietic stem cell activity in the mouse embryo. Immunity 1994;1:291-301.

16 Medvinsky A, Dzierzak E: Definitive hematopoiesis is autonomously initiated by the AGM region. Cell 1996; 86:897-906.

17 Tavian M, Coulombel L, Luton D, Clemente HS, Dieterlen-Lievre F, Peault B: Aorta-associated CD34+ hematopoietic cells in the early human embryo. Blood 1996;87:67-72.

18 Medvinsky AL, Samoylina NL, Muller AM, Dzierzak EA: An early pre-liver intraembryonic source of CFU-S in the developing mouse. Nature 1993;364:64-67.

19 Kumaravelu P, Hook L, Morrison AM, Ure J, Zhao S, Zuyev S, Ansell J, Medvinsky A: Quantitative developmental anatomy of definitive haematopoietic stem cells/long-term repopulating units (HSC/RUs): role of the aorta-gonad-mesonephros (AGM) region and the yolk sac in colonisation of the mouse embryonic liver. Development 2002;129:4891-4899.
20 Ivanovs A, Rybtsov S, Welch L, Anderson RA, Turner ML, Medvinsky A: Highly potent human hematopoietic stem cells first emerge in the intraembryonic aorta-gonad-mesonephros region. J Exp Med 2011; 208:2417-2427.

21 Zovein AC, Hofmann JJ, Lynch M, French WJ, Turlo KA, Yang Y, Becker MS, Zanetta L, Dejana E, Gasson JC, Tallquist MD, Iruela-Arispe ML: Fate tracing reveals the endothelial origin of hematopoietic stem cells. Cell Stem Cell 2008;3:625-636.

22 Lancrin C, Sroczynska P, Stephenson C, Allen T, Kouskoff V, Lacaud G: The haemangioblast generates haematopoietic cells through a haemogenic endothelium stage. Nature 2009;457:892-895.

23 North T, Gu TL, Stacy T, Wang Q, Howard L, Binder M, Marin-Padilla M, Speck NA: Cbfa2 is required for the formation of intra-aortic hematopoietic clusters. Development 1999;126:2563-2575.

24 Wang Q, Stacy T, Binder M, Marin-Padilla M, Sharpe $\mathrm{AH}$, Speck NA: Disruption of the Cbfa2 gene causes necrosis and hemorrhaging in the central nervous system and blocks definitive hematopoiesis. Proc Natl Acad Sci U S A 1996;93:3444-3449.

25 Hirai H, Samokhvalov IM, Fujimoto T, Nishikawa S, Imanishi J, Nishikawa S: Involvement of Runxl in the down-regulation of fetal liver kinase-1 expression during transition of endothelial cells to hematopoietic cells. Blood 2005;106:1948-1955.

26 Liakhovitskaia A, Rybtsov S, Smith T, Batsivari A, Rybtsova N, Rode C, de Bruijn M, Buchholz F, Gordon-Keylock S, Zhao S, Medvinsky A: Runxl is required for progression of CD41+ embryonic precursors into HSCs but not prior to this. Development 2014;141:3319-3323.

27 Corbel C, Salaun J: AlphaIIb integrin expression during development of the murine hemopoietic system. Dev Biol 2002;243:301-311.

28 Mikkola HK, Fujiwara Y, Schlaeger TM, Traver D, Orkin SH: Expression of CD41 marks the initiation of definitive hematopoiesis in the mouse embryo. Blood 2003;101:508-516 
29 Klump H, Schiedlmeier B, Baum C: Control of selfrenewal and differentiation of hematopoietic stem cells: HOXB4 on the threshold. Ann N Y Acad Sci 2005; 1044:6-15.

30 Lie ALM, Marinopoulou E, Li Y, Patel R, Stefanska M, Bonifer C, Miller C, Kouskoff V, Lacaud G: RUNX1 positively regulates a cell adhesion and migration program in murine hemogenic endothelium prior to blood emergence. Blood 2014;124:e11-20.

31 Sawamiphak S, Kontarakis Z, Stainier DY: Interferon gamma signaling positively regulates hematopoietic stem cell emergence. Dev Cell 2014;31:640-653.

32 Swiers G, Baumann C, O’Rourke J, Giannoulatou E Taylor S, Joshi A, Moignard V, Pina C, Bee T, Kokkaliaris $\mathrm{KD}$, Yoshimoto $\mathrm{M}$, Yoder MC, Frampton J, Schroeder T, Enver T, Gottgens B, de Bruijn MF: Early dynamic fate changes in haemogenic endothelium characterized at the single-cell level. Nat Commun 2013;4:2924.

33 Sroczynska P, Lancrin C, Kouskoff V, Lacaud G: The differential activities of Runxl promoters define milestones during embryonic hematopoiesis. Blood 2009; 114:5279-5289.

34 Challen GA, Goodell MA: Runx1 isoforms show differential expression patterns during hematopoietic development but have similar functional effects in adult hematopoietic stem cells. Exp Hematol 2010;38: 403-416.

35 Webber BR, Iacovino M, Choi SH, Tolar J, Kyba M, Blazar BR: DNA methylation of Runx1 regulatory regions correlates with transition from primitive to definitive hematopoietic potential in vitro and in vivo. Blood 2013;122:2978-2986.
36 Richard C, Drevon C, Canto PY, Villain G, Bollerot K, Lempereur A, Teillet MA, Vincent C, Rossello Castillo C, Torres M, Piwarzyk E, Speck NA, Souyri M, Jaffredo $\mathrm{T}$ : Endothelio-mesenchymal interaction controls runx 1 expression and modulates the notch pathway to initiate aortic hematopoiesis. Dev Cell 2013;24:600-611.

37 Lee Y, Manegold JE, Kim AD, Pouget C, Stachura DL, Clements WK, Traver D: FGF signalling specifies haematopoietic stem cells through its regulation of somitic Notch signalling. Nat Commun 2014;5:5583.

38 Pouget C, Peterkin T, Simoes FC, Lee Y, Traver D, Patient R: FGF signalling restricts haematopoietic stem cell specification via modulation of the BMP pathway. Nat Commun 2014;5:5588

39 Clements WK, Kim AD, Ong KG, Moore JC, Lawson ND, Traver D: A somitic Wnt16/Notch pathway specifies haematopoietic stem cells. Nature 2011;474:220224.

40 Kanz D, Konantz M, Alghisi E, North TE, Lengerke C: Endothelial-to-hematopoietic transition: Notch-ing vessels into blood. Ann N Y Acad Sci 2016;1370:97108.

41 Jackson M, Axton RA, Taylor AH, Wilson JA, Gordon-Keylock SA, Kokkaliaris KD, Brickman JM, Schulz H, Hummel O, Hubner N, Forrester LM: HOXB4 can enhance the differentiation of embryonic stem cells by modulating the hematopoietic niche. Stem Cells 2012;30:150-160.

42 Robert-Moreno A, Espinosa L, de la Pompa JL, Bigas A: RBPjkappa-dependent Notch function regulates Gata2 and is essential for the formation of intra-embryonic hematopoietic cells. Development 2005;132: $1117-1126$.
43 Nottingham WT, Jarratt A, Burgess M, Speck CL, Cheng JF, Prabhakar S, Rubin EM, Li PS, Sloane-Stanley J, Kong ASJ, de Bruijn MF: Runx1-mediated hematopoietic stem-cell emergence is controlled by a Gata/Ets/SCL-regulated enhancer. Blood 2007;110: $4188-4197$.

44 Bee T, Ashley EL, Bickley SR, Jarratt A, Li PS, SloaneStanley J, Gottgens B, de Bruijn MF: The mouse Runx1 +23 hematopoietic stem cell enhancer confers hematopoietic specificity to both Runx1 promoters. Blood 2009;113:5121-5124.

45 Wilson NK, Foster SD, Wang X, Knezevic K, Schutte J, Kaimakis P, Chilarska PM, Kinston S, Ouwehand WH, Dzierzak E, Pimanda JE, de Bruijn MF, Gottgens B Combinatorial transcriptional control in blood stem/ progenitor cells: genome-wide analysis of ten major transcriptional regulators. Cell Stem Cell 2010;7:532544.

46 de Pater E, Kaimakis P, Vink CS, Yokomizo T, Yamada-Inagawa $T$, van der Linden R, Kartalaei PS, Camper SA, Speck N, Dzierzak E: Gata2 is required for HSC generation and survival. J Exp Med 2013;210 2843-2850.

47 Tanaka H, Matsumura I, Itoh K, Hatsuyama A, Shikamura M, Satoh Y, Heike T, Nakahata T, Kanakura Y: HOX decoy peptide enhances the ex vivo expansion of human umbilical cord blood CD34+ hematopoietic stem cells/hematopoietic progenitor cells. Stem Cells 2006;24:2592-2602.

48 McKinney-Freeman SL, Naveiras O, Yates F, Loewer S Philitas M, Curran M, Park PJ, Daley GQ: Surface antigen phenotypes of hematopoietic stem cells from embryos and murine embryonic stem cells. Blood 2009; 114:268-278. 